\title{
Corrigendum to "A New Method for Puerarin Determination Based on Poly (Alizarin Red S/Graphene) Modified Electrode" [Int. J. Electrochem. Sci., 11(2016) 9949-9958]
}

Weili Zhang ${ }^{*}$, Pingping Zhang, Hua Zhang, Jinyi Qin, Qinglu Wang

College of Pharmacy, Key Laboratory of Biomedical Engineering and Technology in Universities of Shandong, Qilu Medical University, Zibo 255213, P. R. China.

*E-mail: zhangweili4619563@126.com

doi: $10.20964 / 2017.01 .201$

Received: 10 December 2016 / Accepted: 10 December 2016 / Published: 12 December 2016

Firstly, scheme 1 is missed on page 9953 in the published version. The scheme 1 is shown below. Consequently, the scheme on page 9955 should be scheme 2.<smiles>O=C1c2ccccc2C(=O)c2c1cc(S(=O)(=O)[O-])c(O)c2O</smiles>

Scheme 1 The possible mechanism of electropolymerization of ARS on GCE.

Secondly, the data for linear range and detection limit in "Conclusions" section are incorrect. The corrected linear range and detection limit are $1.0 \times 10^{-7} \sim 7.5 \times 10^{-4} \mathrm{~mol} / \mathrm{L}$ and $3.4 \times 10^{-8} \mathrm{~mol} / \mathrm{L}$, respectively.

The authors would like to apologize for inconvenience caused.

(C) 2017 The Authors. Published by ESG (www.electrochemsci.org). This article is an open access article distributed under the terms and conditions of the Creative Commons Attribution license (http://creativecommons.org/licenses/by/4.0/). 